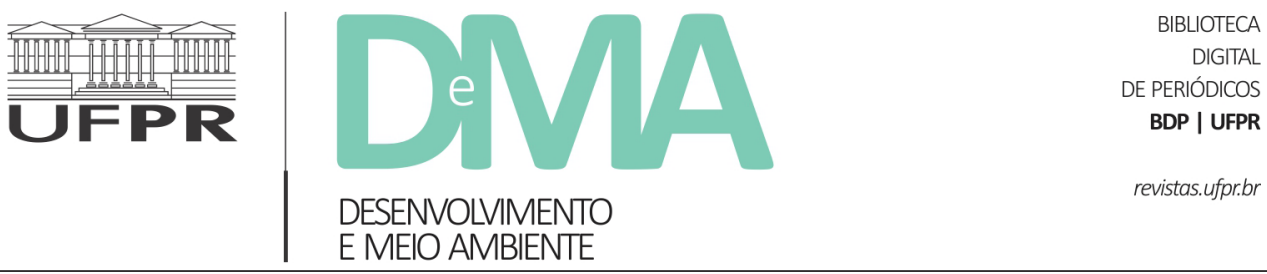

\title{
Desenvolvimento e ciências ambientais: analisando as redes temáticas da agenda de pesquisa da área no Brasil
}

\section{Development and environmental sciences: analysing thematic networks of the research agenda in Brazil}

\author{
Natália Tavares AZEVEDO ${ }^{*}$, Ivan Jairo JUNCKES², Edson Armando SILVA ${ }^{3}$ \\ ${ }^{1}$ Universidade Federal do Paraná (UFPR) Litoral, Matinhos, PR, Brasil. \\ ${ }^{2}$ Universidade Federal do Paraná (UFPR) Litoral, Matinhos, PR, Brasil. \\ ${ }^{3}$ Universidade Estadual de Ponta Grossa (UEPG), Ponta Grossa, PR, Brasil. \\ *E-mail de contato: natytav@yahoo.com.br
}

Artigo recebido em 28 de abril de 2020, versão final aceita em 16 de dezembro de 2020, publicado em 6 de maio de 2020.

RESUMO: $\quad$ A emergência da questão ambiental na década de 1960 levou à compreensão dos efeitos globais das atividades humanas sobre o sistema terrestre, conduzindo os olhares para a questão dos modelos de desenvolvimento, em suas múltiplas dimensões. É nesse cenário que surgem as ciências ambientais, em busca de abordagens menos fragmentadas e mais integrativas, com um caráter marcadamente interdisciplinar. No Brasil, esse campo passa a se constituir na década de 1980, chegando ao seu grau mais alto de institucionalização em 2011, por meio da criação de uma nova área de avaliação no âmbito da pós-graduação. Neste artigo, apresentam-se resultados da pesquisa que teve como objetivo identificar as comunidades temáticas que constituem a agenda de pesquisa sobre a questão do desenvolvimento no âmbito das ciências ambientais brasileiras, voltando o foco da análise para a produção da pós-graduação, particularmente as teses e dissertações entre 1987 e 2017. Para tanto, utilizou-se a bibliometria relacional e a análise de redes de palavras-chave dos trabalhos como metodologia, a partir da identificação de 1061 teses e dissertações que utilizaram o termo desenvolvimento entre suas palavras-chave. Como resultados, identificou-se $41 \%$ das teses e dissertações no Nordeste, marcando uma forte concentração regional. Identificaram-se 10 comunidades temáticas, sendo as maiores as que tratam de políticas públicas, com recortes espacializados, com destaque para o rural e ênfase na dimensão institucional, e a com foco no turismo como agente do desenvolvimento local. As outras comunidades identificadas foram economia-tecnologia, socioambiental-impacto, agricultura-familiar, indicador-água, saúde-humano, resíduo-sólido, pesca-indústria e crédito-limpo. Aponta-se, assim, para a diversidade temática como uma importante componente do debate sobre desenvolvimento nas ciências ambientais, ao mesmo tempo em que se destaca a potência da bibliometria relacional e da análise de redes para compreensão da produção da ciência a partir de grandes repositórios documentais. 
Palavras-chave: ciências ambientais; desenvolvimento; análise de redes; agenda de pesquisa; bibliometria relacional.

ABSTRACT: The emergency of environmental concerns in the 1960s led to the comprehension of the human activity global effects on the earth system, drawing attention to the issue of development models and their multiple dimensions. The environmental sciences appeared in this scenery seeking less fragmented and more integrative approaches with a markedly interdisciplinary character. In Brazil, this field started to be constituted in the 1980s, reaching its institutionalization peak in 2011, through the creation of a new evaluation area at the post-graduation level. This paper presents the results of a study that aimed at identifying the thematic communities from the research agenda on the issue of development in Brazilian environmental sciences. The analysis focuses on the post-graduation production, mainly theses, and dissertations published between 1987 and 2017. With this purpose, the methodology included relational bibliometrics and keyword networks from the identification of 1,061 theses and dissertations that used the term development among their keywords. As a result, $41 \%$ of the theses and dissertations were found to be produced in the Northeast, showing high regional concentration. Ten thematic communities were identified, and among these the larger ones were those addressing public policies, with spatialized trimming, highlighting the rural environment and the institutional dimension, and focus on tourism as a local development agent. The other communities identified were economy-technology, socioenvironmental-impact, agriculture-family, indicator-water, health-human, residue-solid, fishingindustry, and credit-clear. Therefore, thematic diversity is shown as an important component in the debate over development in environmental sciences, and at the same time, relational bibliometrics and word network analysis have their potential highlighted concerning the understanding of science production from large document collections.

Keywords: environmental science; development; research agenda; network analysis; relational bibliometrics.

\section{Introdução}

As ciências ambientais surgem na década de 1960 como um campo específico do conhecimento, intrinsecamente relacionado ao reconhecimento dos problemas ambientais como uma questão relevante na esfera pública e marcado por forte interdisciplinaridade. Como aponta Pierri (2005), nesse momento uma série de informes científicos contribuem para a compreensão da crise ambiental. Entre estes estão o seminal Silent Spring (Primavera Silenciosa), de Rachel Carson (1962), Science and Survival (Ciência e Sobrevivência), de Barry Commoner (1966), The Population Bomb (A Bomba Populacional), de Paul Erlich (1968), bem como o famoso relatório do Clube de Roma, Limits to Growth (Limites do Crescimento), dirigido por
Dennis Meadows (1972). Estes são apenas alguns dos muitos estudos publicados por biólogos, economistas, agrônomos e cientistas de diversas áreas questionando o crescimento econômico e seus efeitos sobre a natureza, configurando um cenário inicial das ciências ambientais.

Surgiram diferentes tipos de denúncia sobre os efeitos deletérios sobre os sistemas ecológicos do crescimento econômico, da intensificação dos níveis de utilização dos recursos naturais renováveis e não renováveis, do uso de insumos químicos e do crescimento populacional. Progressivamente, desenvolveu-se o entendimento de que, mais do que uma série de problemas ambientais locais, a sinergia entre as atividades antrópicas e seus efeitos sobre a biosfera têm caráter global e que elas poderiam ameaçar a própria continuidade das sociedades hu- 
manas, o que lhe conferia um caráter radicalmente novo devido à sua escalaridade (Buttel et al., 1990; Foladori, 2005).

Em face do reconhecimento da globalidade da crise, das assimetrias entre os países centrais e periféricos e dos limites de uma visão estritamente econômica, a trajetória histórica da discussão em torno da crise ambiental conduziu os olhares para a questão do desenvolvimento em suas múltiplas dimensões, levando para o centro do debate a temática dos modelos ou estilos de desenvolvimento. Inicialmente, ganhou espaço a noção de ecodesenvolvimento, formulada por Maurice Strong e desenvolvida por Ignacy Sachs (Estenssoro, 2015). Tal noção postulava um desenvolvimento de caráter endógeno, respeitando as características de cada local ou território. Porém, o ecodesenvolvimento acabou perdendo espaço para a noção de desenvolvimento sustentável do chamado Relatório Brundtland (Montibeller Filho, 2008), uma noção mais "neutra" e menos crítica à ideia de crescimento econômico.

Um aparente consenso se consagrou em torno de uma fórmula do desenvolvimento que levasse em consideração os aspectos econômicos, ecológicos e sociais, ainda que a noção tenha se tornado frágil e tenha sido adotada por atores dos mais distintos matizes políticos com proposições bastante diferentes entre si. Estas distintas posições vão desde perspectivas baseadas em reformismos fracos, que visam sustentar o crescimento econômico, com uma preocupação ecológica e social limitada, até perspectivas transformacionistas, que situam nas relações sociais de produção capitalistas as causas da falha metabólica na relação sociedade - natureza, e que veem na superação desse sistema o caminho para a sustentabilidade em sentido amplo (Lélé, 1991; Hopwood et al., 2005).

Nesse cenário, emergem - no âmbito acadêmico - as ciências ambientais, como tentativa de superar a fragmentação do conhecimento científico sobre o meio ambiente, em busca de perspectivas interdisciplinares, integrativas e sistêmicas (Cunningham \& Cunningham, 2008; Vieira, 2009). Muitos pesquisadores passaram a reconhecer a necessidade de ruptura dos diques das disciplinas (Floriani, 2000), na perspectiva da construção da interdisciplinaridade como modo mais adequado de lidar com os grandes desafios colocados pelos problemas ambientais contemporâneos (Ferreira, 2006). Esses esforços consubstanciaram a emergência das ciências ambientais, institucionalizadas por meio de programas de graduação e pós-graduação para a formação de novos quadros profissionais (Philippi Jr. et al., 2000).

A institucionalização desse novo campo do conhecimento se dá de forma gradual, e o próprio entendimento sobre o que constitui efetivamente as ciências ambientais ainda é objeto de disputas. Nas estruturas acadêmicas de diferentes países, há distintas formas de organização institucional para abrigar as ciências emergentes dedicadas à questão ambiental. Em alguns países, há uma clara diferenciação entre estudos ambientais e ciências ambientais, abrigando ciências humanas e sociais, no primeiro caso, e biofísicas e engenharias, no outro caso, mantendo a separação entre as "duas culturas" (Santos, 2008). Porém, mesmo nesses contextos há um entendimento cada vez maior de que os problemas ambientais globais contemporâneos necessitam de perspectivas interdisciplinares para serem enfrentados e de que o debate sobre desenvolvimento e sustentabilidade está no centro dessa 
interação entre diferentes disciplinas (Buarque et al., 2014; Castree et al., 2014).

No Brasil, um marco da trajetória das ciências ambientais ocorre com a realização do $1^{\circ}$ Seminário Nacional sobre Universidade e Meio Ambiente, em 1986, desdobrando-se na década de 1990 em apoio e indução por meio de programas como o Programa de Apoio ao Desenvolvimento da Ciência e Tecnologia (PADCT) e seu subprograma Ciências Ambientais (Rocha, 2003). A área encontra seu grau mais alto de institucionalização em 2011, com a criação da Câmara de Avaliação em Ciências Ambientais (CACiAmb), da Coordenação de Aperfeiçoamento de Pessoal de Nível Superior (CAPES), que aglutinou os programas de pós-graduação que se identificam como pertencentes à área (Philippi Jr. et. al., 2013). Desde então, CACiamb vem experimentando um forte crescimento, somando 141 programas de pós-graduação em 2020, nas cinco regiões do país.

O debate sobre desenvolvimento e sustentabilidade constitui o pano de fundo sob o qual se desenvolvem as ciências ambientais. Todavia, não são todas as pesquisas que assumem o tema de forma mais direta e explícita, uma vez que a agenda de pesquisa nas ciências ambientais é bastante ampla, contando com pesquisadores formados em distintas áreas disciplinares. É nessa intersecção entre o debate sobre o desenvolvimento e a constituição das ciências ambientais como um campo próprio marcado pela interdisciplinaridade que se situa a presente pesquisa.

O presente trabalho investiga as temáticas que os pesquisadores em ciências ambientais desenvolvem quando problematizam diretamente a questão do desenvolvimento, tendo como ponto de partida o seguinte questionamento: qual agenda de pesquisa se constitui no país dentro da área de ciências ambientais em torno da temática do desenvolvimento? A partir desta questão, estabeleceu-se como objetivo identificar as comunidades temáticas que constituem a agenda de pesquisa sobre desenvolvimento no âmbito das ciências ambientais brasileiras, focalizando a produção da pós-graduação, particularmente as teses e dissertações.

Para executar a pesquisa, foi consultado o Banco de Teses e Dissertações disponibilizado pela CAPES, particularmente os metadados divulgados no portal Dados Abertos dessa agência. Foram identificadas todas as teses e dissertações dos programas que compõem atualmente a área de Ciências Ambientais (ano-base 2017), mesmo nos períodos anteriores à constituição da CACiamb, contemplando o período de 1987 a 2017. Em seguida, foram selecionadas todas as teses e dissertações que utilizaram o termo "desenvolvimento" em suas palavras-chave ou título, assumindo que esta escolha dos autores decorre da relevância do debate sobre desenvolvimento na pesquisa realizada. A partir disso, constituiu-se uma base de dados com as palavras-chave desses trabalhos, usada na análise de redes (ARS) para identificar as comunidades temáticas que envolvem a questão do desenvolvimento nas ciências ambientais.

A pesquisa contribui em duas esferas do conhecimento: (i) para a reflexividade do próprio campo das ciências ambientais brasileiras, identificando elementos da sua agenda de pesquisa, e (ii) para a operacionalização da exploração de grandes bancos de dados documentais por meio da utilização de uma metodologia inovadora que se aproxima do que Thelwall (2008) descreve como bibliometria relacional, que investiga a estrutura cognitiva e/ou semântica dos campos de pesquisa. 
O artigo está estruturado em seis seções, incluindo a introdução. Na segunda seção, são apresentados elementos teóricos para compreensão das agendas de pesquisa na área de ciências ambientais, com foco na questão do desenvolvimento. Na terceira, apresenta-se a análise de redes e a bibliometria relacional como metodologia para a pesquisa, explicitando os procedimentos adotados. A quarta seção traz dados referentes à pós-graduação em ciências ambientais no país, sua evolução e distribuição regional. Na quinta seção, as comunidades temáticas formadas em torno da questão do desenvolvimento são apresentadas e discutidas. A sexta seção corresponde às considerações finais do artigo.

\section{Ciências ambientais e desenvolvimento: elementos para reflexividade do campo e compreensão das agendas de pesquisa}

As ciências ambientais emergiram num período de grandes mudanças, em meio a processos compreendidos por alguns autores como a sobreposição de diferentes crises - econômicas, ecológicas, sociais, alimentares, energéticas, científicas e de conhecimentos - que se configuram mais propriamente como um período de crise civilizatória (Leff, 2006). O alcance e magnitude das ações antrópicas sobre o sistema terrestre são tais que levaram à designação (ainda não "oficial") de uma nova época geológica, o antropoceno, proposto por Crutzen (2002). Essa época coincidiria com a ascensão da revolução industrial e do sistema capitalista - com suas desigualdades e assimetrias (Moore, 2017), exigindo mudanças na forma de produção do conhecimento para enfrentar os desafios ambientais decorrentes.
A problemática ambiental abriu um novo campo do saber - e do poder no saber - que se desdobra nas estratégias discursivas e nas políticas de desenvolvimento sustentável (Leff, 2006). A disputa entre os atores envolvidos nas questões ambientais envolve distintas posições e compreensões sobre como enfrentá-la, que engendram agendas políticas e de pesquisa na área de ciências ambientais. Tim Forsyth (2003) destaca como as relações entre política e ciências ambientais não são neutras, pois as definições das agendas de pesquisa e a forma de compreender os problemas ambientais são elas mesmas imersas em valores e influenciados por processos políticos e de disputas de poder que perpassam a indução e o financiamento de pesquisas, por meio da política científica e tecnológica.

Essas diferentes posições não envolvem apenas escolhas teóricas e políticas, mas estão ligadas também a certa geopolítica do conhecimento, aos lugares de enunciação dos pesquisadores e aos dilemas e problemas contextuais que eles enfrentam. Pesquisadores dos países em desenvolvimento, por exemplo, tendem a tematizar a problemática ambiental de forma distinta aos dos países desenvolvidos, em face do contexto social, econômico e ecológico, além das tradições e instituições acadêmicas existentes que coordenam e financiam as ciências.

Vanhulst \& Zaccai (2016), em um mapeamento sobre o debate acadêmico em torno do desenvolvimento sustentável na América Latina, corroboram esse entendimento. Os latino-americanos, segundo os autores, participam ativamente do debate sobre a temática em termos globais, porém adotando uma posição crítica, se aproximando da ecologia social, da ecologia política, da economia ecológica e do pensamento complexo. Indicam que os pesquisadores e pensadores latino-americanos no campo 
do desenvolvimento sustentável se apropriam e referenciam os autores europeus e norte-americanos, porém a partir de vieses muitas vezes críticos, apontando os limites da modernidade eurocentrada e dos paradigmas hegemônicos de desenvolvimento e da modernização ecológica.

Como apontado, as denominações dos novos campos (inter)disciplinares também apresentam variações, com participação de distintas disciplinas em diferentes arranjos. Ciências ambientais, estudos ambientais, ciências da sustentabilidade são nomenclaturas que se encontram em diferentes cursos e programas de formação nos vários níveis, em diferentes países, mas que têm em comum adotar como objeto questões relacionadas à interface sociedade - natureza. De forma geral, essas áreas, embora venham apresentando crescimento contínuo, ainda não são plenamente institucionalizadas dentro das estruturas acadêmicas e universitárias. Não são apenas pesquisadores que se encontram diretamente filiados aos programas de ciências ambientais que contribuem para a compreensão dos problemas ambientais. Pesquisadores filiados institucionalmente a outras disciplinas e departamentos também realizam pesquisas na área e publicam seus resultados em periódicos de diferentes áreas do conhecimento. Além disso, as questões ambientais e do desenvolvimento sustentável são objeto de interesse e pesquisas também de variados think tanks e organizações não-governamentais.

As diferentes concepções sobre as ciências ambientais - e a variação das nomenclaturas utilizadas para expressar o conhecimento científico interdisciplinar que envolve a questão ambiental - resultam em boa medida da própria compreensão da noção de ambiente. Como aponta Guevara (2005), as diferentes formas pelas quais as socie- dades humanas classificam o saber e os campos do conhecimento dependem da experiência concreta desenvolvida em função da solução de determinados problemas, assim como das representações mentais e dos conceitos com que uma população mediatiza sua relação com o mundo. Essas construções conceituais, que são espaço-temporal e culturalmente situadas, condicionam a capacidade de percepção.

Algumas tradições de pensamento entendem, a partir de uma visão dicotômica entre sociedade e natureza, o meio ambiente como o entorno biofísico que serve de base e cenário para as atividades humanas. Nessa perspectiva, os problemas ambientais são compreendidos como localizados fora da atividade social, como problemas técnicos, para os quais as soluções se movem no âmbito tecnológico ou na geração de normas para evitar a destruição dos recursos, ou em incentivos para promover condutas desejáveis, reduzindo a enfoques normativos. Nessa forma de concepção, as ciências sociais e as humanidades são apenas marginalmente consideradas como parte das ciências ambientais, que teriam como disciplinas privilegiadas as ciências naturais e biofísicas, básicas e aplicadas, e as engenharias (Guevara, 2005). Desde essa perspectiva, as ciências ambientais seriam então dominadas por essas disciplinas, e os estudos ambientais e a ciência da sustentabilidade seriam outros campos do conhecimento, ainda que relacionados, mais afeitos às ciências sociais e às humanidades.

Seguindo o entendimento de Castree (2016), pode-se depreender que o mainstream das ciências ambientais nos países desenvolvidos e nos principais centros de produção científica (Europa e Estados Unidos) tem como construção dominante o eixo STEM (Science, Technology, Engineering and Mathematics - ciência, tecnologia, engenharia 
e matemática). Segundo o autor, por muito tempo o eixo STEM tem dominado a pesquisa sobre como as pessoas estão alterando atmosfera, biosfera, criosfera, hidrosfera e litosfera, mas necessita-se urgentemente entender e buscar alterar o comportamento humano para que nosso planeta siga habitável para todas as pessoas. Castree (2016), reforçando a argumentação de artigo publicado em colaboração com vários outros pesquisadores (Castree et al., 2014), aponta que apenas certas ciências sociais de caráter positivista, dotadas de afinidades eletivas com as ciências biofísicas que dominam as ciências ambientais, vêm tendo espaço na colaboração interdisciplinar do campo, particularmente o mainstream da economia, da psicologia comportamentalista e da ciência política. Outras formas de ciências sociais e humanidades e formas mais amplas de problematizar a relação sociedade $\mathrm{x}$ natureza contribuiriam para conceber respostas aos grandes problemas globais contemporâneos.

Como um campo científico emergente e por causa do seu caráter fortemente normativo, as ciências ambientais são movimentadas por controvérsias. São comuns debates epistemológicos, sobre as condições de produção do conhecimento ambiental, sobre os delineamentos de métodos e objetos da área. Essa reflexividade é constituinte e constitutiva do próprio desenvolvimento do conhecimento científico, como aponta Bourdieu (2004). Todavia, estudos sobre seus resultados, efeitos e impactos ainda são incipientes, embora venham despertando interesse crescente na comunidade acadêmica ${ }^{1}$.
Nos últimos anos crescem as atenções voltadas às ciências ambientais, particularmente em face da centralidade que elas vêm ganhando em termos das políticas ambientais e do próprio debate político em geral, dada a crescente percepção sobre as mudanças ambientais globais e os seus efeitos sobre as sociedades. Em tempos de ofensivas negacionistas do caráter antropogênico destas mudanças ambientais, há um tensionamento ainda maior sobre a comunidade científica na busca de legitimação do campo (Björnberg et al., 2017).

Associado ao crescente interesse das agências gestoras e financiadoras da atividade científica na mensuração da produção sob sua responsabilidade, cresceu a atenção dada ao uso de estratégias cientométricas e bibliométricas na avaliação da produção científica. Uma série de estudos que visam compreender tantos os processos de produção do conhecimento científico quanto seus resultados, em termos qualitativos e quantitativos, vem sendo desenvolvida, compondo os estudos sociais da ciência, a sociologia da ciência, a cientometria e a bibliometria (Hayashi, 2012).

Um dos elementos-chave na compreensão da atividade científica é a identificação e compreensão das agendas de pesquisa dos distintos campos e áreas do conhecimento. É certo que a escolha dos temas de pesquisa, dos objetos e do método não reflete meramente as opções individuais do pesquisador, pois estão imersas em campos científicos que, embora gozem de relativa autonomia em relação ao contexto social mais geral, são profundamente

\footnotetext{
${ }^{1}$ Por exemplo, Bettercourt e Kaur, Evolution and structure of sustainabilty Science (2011); Hassan, Haddawy e Zhu, A bibliometric study of the world's research activity in sustainable development and its sub-areas using scientific literature (2013); Butter e Van Raan, Identification and analysis of the highly cited knowledge base of sustainability science (2011); Cavalcanti e Leite; Interdisciplinaridade e estudos métricos da informação: contribuição para a análise nas Ciências Ambientais, 2019, entre outros.
} 
influenciados por ele. Segundo Floriani (2000), o conhecimento científico é um campo de disputas materiais e simbólicas, no qual ocorrem conflitos de diversas ordens: econômicos, associados a inovações tecnológicas e aos mercados; políticos, como disputas por hegemonia, poder e prestígio nas instituições e entre pesquisadores; filosóficos, na forma de debates acirrados sobre concepções teórico-metodológicas e sobre a natureza e finalidade das ciências; e culturais - maneiras de apropriação e de representação da natureza e transformação da matéria - simbolização que envolve crenças e rejeições das cosmovisões.

Uma agenda de pesquisa pode ser definida como um conjunto organizado de ferramentas (teorias, metodologias, tecnologias, etc.) e instituições (normas, padrões de comportamento, convenções, etc.), que organizam a produção científica em contextos históricos específicos, demarcados por uma conduta de ação do cientista que é socialmente compartilhada por seus pares. Sustenta-se em uma densa rede de atores que moldam instituições e o espaço material sobre o qual o conhecimento será produzido. Desta forma, considera-se a formação de uma agenda de pesquisa como um processo coletivo, em que a informação científica é construída por uma intensa negociação entre atores que trabalham em contextos organizacionais previamente estabelecidos (Silva \& Costa, 2015).

Uma agenda de pesquisa supõe um consenso entre a comunidade de pesquisadores sobre as fronteiras de um campo de conhecimento, as entidades relevantes do universo de análise, as questões legítimas a serem investigadas e as técnicas adequadas de investigação (Silva \& Costa, 2015). Um dos aspectos a destacar dentro das agendas de pesquisa, é, portanto, o das questões levantadas pelos pesquisadores. Isso se expressa, além das escolhas teóricas e metodológicas, nos temas escolhidos, que podem ser investigados, entre outras formas, a partir do léxico, das escolhas das palavras pelos pesquisadores.

\section{3. $O$ uso da análise de redes e da bibliometria relacional como metodologia e os procedimentos da pesquisa}

Uma das dimensões da agenda de pesquisa de um campo é o das questões levantadas pelos pesquisadores, que podem ser compreendidas a partir das temáticas trabalhadas. Para analisar a agenda nas ciências ambientais em torno da questão do desenvolvimento, optou-se por utilizar, além de estatísticas descritivas, uma abordagem relacional. Isso implica o uso da análise de redes a partir das palavras-chave das teses e dissertações, de forma a identificar as comunidades temáticas.

A análise de redes é utilizada aqui como uma técnica ligada à bibliometria relacional que, segundo Thelwall (2008), se dirige a relações dentro da pesquisa, como a estrutura cognitiva dos campos, o surgimento de novas frentes de pesquisa ou de padrões nacionais e internacionais de coautoria. A bibliometria relacional difere da bibliometria avaliativa, que tem como foco avaliar o impacto do trabalho acadêmico, particularmente por meio da quantificação de citações e do uso de índices que medem a influência de autores e seus trabalhos em seu campo de pesquisa e o impacto dos próprios periódicos. Essas métricas têm influenciado cada vez mais a tomada de decisão no âmbito do financiamento de pesquisas científicas e tecnológicas (Thelwall, 2008; Hayashi, 2012). 
No âmbito das bibliometrias relacionais, a análise de redes tem se dirigido mais aos estudos de cocitação e à composição de redes de colaboração entre pesquisadores e instituições. Porém, sua utilização a partir das palavras-chave de textos também passou a ser utilizada nos últimos anos. Yi \& Choi (2012) apontam a análise das redes de palavras-chave como uma abordagem alternativa pertinente, apontando que as palavras-chave são um veículo fundamental do conhecimento científico. Como colocam os autores, ao escolherem as palavras-chave, os pesquisadores as consideram como uma forma de identificar um foco específico de pesquisa. Segundo Yi \& Choi (2011), ao estudarem as sub-redes formadas por palavras-chave fortemente associadas, é possível identificar comunidades semânticas que correspondem à agenda de grupos de pesquisadores com interesses similares. Segundo esses autores, a análise de redes de palavras pode ajudar a compreender a estrutura do conhecimento científico em um campo, ideia corroborada por Radhakrishnan et al. (2017).

Na cientometria, cresce o interesse pelo uso da análise de redes, tanto de citações quanto de redes semânticas, para análise das paisagens científicas (scientific landscapes), tal como faz Raimbault (2019) no trabalho em que explora a interdisciplinaridade em periódicos do campo da geografia.

Essa metodologia de uso da análise de redes para construir topologias temáticas e redes semânticas a partir das palavras-chave foi utilizada também por Silva \& Pereira (2016), ao analisar a produção da Revista de História Regional em seus 20 anos de existência. Schodl et al. (2017) utilizaram metodologia similar, analisando pesquisas sobre sustentabilidade na produção suína; Feretti et al. (2018) a adotaram para analisar redes sociais em ciência política. Isso expressa o interesse crescente pelo uso de abordagens relacionais no estudo da produção científica por meio das palavras-chave. Pode-se dizer, portanto, que o estudo das palavras-chave utilizadas em trabalhos de um determinado campo ajuda a compreender suas agendas de pesquisa.

Como apontam Silva \& Silva (2016), com base em Paranyushkin (2011), ao analisar bases documentais de grande porte, um dos procedimentos é selecionar as unidades, termos ou textos inteiros a serem explorados em seus relacionamentos. No caso da presente pesquisa, os termos são palavras-chave das dissertações e teses da área de ciências ambientais defendidas entre 1987 e 2017 . Entende-se que a escolha das categorias e o seu indicativo nas palavras-chave pelos autores revelam suas inclinações teóricas, temáticas e epistemológicas, podendo-se a partir daí se desvelar e dimensionar as comunidades temáticas relacionadas ao desenvolvimento nas ciências ambientais.

Como coloca Newman (2010), há duas questões que atraem pesquisadores de diversos campos para o uso da análise de redes como metodologia de pesquisa: (i) quais são os nós mais centrais dentro do universo de nós que podem compor uma rede?; (ii) que papel esses nós centrais desempenham em relação aos demais e que tipos de agrupamentos, comunidades ou correlações entre grupos de nós permitem diferenciá-los dos demais, revelando algum tipo de regularidade a ser analisada?

A base de dados utilizada para a presente pesquisa foi o catálogo de teses e dissertações disponibilizado pela Capes (http://dadosabertos.capes. gov.br). Nesta base encontram-se informações sobre os trabalhos defendidos na pós-graduação brasileira entre os anos de 1987 e 2017. Foram consideradas teses e dissertações, tanto de mestrado acadêmico 
quanto profissional, compreendendo o período de 1990 a 2017. O primeiro trabalho defendido na área de ciências ambientais no Brasil foi uma dissertação de mestrado, em 1994, no Programa de Ciência Ambiental - PROCAM/USP (criado em 1990).

Para o desenvolvimento da pesquisa, foram identificados todos os programas que pertencem atualmente à área de ciências ambientais, informação disponível na Plataforma Sucupira, da Capes (http://sucupira.capes.gov.br). Esse passo foi fundamental para identificação das teses e dissertações da área no período anterior ao de criação da área de avaliação Ciências Ambientais da Capes, em 2011, período esse em que os programas eram filiados a outras áreas. Considerou-se que todos os programas que aderiram à nova área de ciências ambientais podem ser compreendidos como integrantes do campo mesmo antes da criação da área de avaliação própria. Foi necessária a busca na base de dados das teses e dissertações de cada um dos programas para todos os anos, o que resultou num total de 12.655 teses e dissertações defendidas entre os anos de 1987 e 2017.

Após a identificação dos trabalhos-alvo, foi realizada busca entre as palavras-chave e os títulos daqueles que mencionaram o termo desenvolvimento. Em seguida, foi realizada a desambiguação, excluindo os trabalhos nos quais o termo foi utilizado sem fazer referência à problemática do desenvolvimento (como em desenvolvimento de metodologia, desenvolvimento de processos, etc.). Foram excluídas também eventuais duplicatas. $\mathrm{O}$ universo assim construído totalizou 1.061 teses e dissertações.

O passo seguinte foi o tratamento das palavras-chave, com a verificação da grafia e eventuais correções das palavras em registros com problemas de grafia ou com palavras incompletas. Averiguou-se a seleção feita pelos autores e, em caso de insuficiência, foram incluídos termos retirados necessariamente dos resumos. De toda forma, essa intervenção foi mínima, afetando apenas 56 dos 1.061 trabalhos selecionados.

$\mathrm{Na}$ sequência, foi realizado o processo de radicalização (stemming) das palavras, com ajuda do software livre Open Refine 3.1. Nesse passo, agruparam-se palavras com o mesmo radical que ficariam separadas no arquivo por terem sufixos diferentes, como 'o' ou 'a' para indicar gênero, 's' para indicar plural, etc. Sem esses procedimentos, expressões referentes à mesma realidade ficariam em nós diferentes na rede como, por exemplo, pesqueiro, pesqueira, pesca, pescador, pescadora. Nesse passo, foram também separadas palavras-chave compostas de termos independentes, como políticas públicas, recursos hídricos, bacias hidrográficas. Vale notar que esses termos são novamente ligados na análise de redes, uma vez que são parte do mesmo traba1ho, não prejudicando assim o sentido cognitivo e semântico dos termos.

Inicialmente, apenas a palavra desenvolvimento foi suprimida, pois está presente em todos os trabalhos, uma vez que foi o critério para inclusão na pesquisa, e sua manutenção geraria um nó superestimado. Após alguns testes com a rede, foram também retiradas as palavras sustentável (e correlatas, como sustentabilidade) e ambiental, presentes em quase todos trabalhos, criando nós superestimados que distorciam os resultados na observação das comunidades temáticas. Esse passo se justifica porque os trabalhos são da área de ciências ambientais e, ao tratar o tema do desenvolvimento desde esse campo do conhecimento, o fazem na perspectiva da sustentabilidade. Portanto, mais do que identificadores 
temáticos, essas palavras-chave são marcadoras do campo das ciências ambientais; por isso, foram removidas. O resultado desse processo é uma planilha eletrônica que vincula cada trabalho (source) às palavras-chave (target) nele utilizadas, já preparada para importação no software livre Gephi 0.9.2 para elaboração das redes (Tabela 1).

TABELA 1 - Exemplo de planilha trabalho-palavra exportada para o Gephi.

\begin{tabular}{ccc}
\hline Source & Target & Type \\
\hline 12 & Rio-92 & undirected \\
12 & Conferência & undirected \\
12 & Nações & undirected \\
12 & Unidas & undirected \\
12 & Comunicação & undirected \\
20 & Agricultura & undirected \\
20 & Tradicional & undirected \\
20 & Semiárido & undirected \\
21 & Caprinocultura & undirected \\
21 & Agropecuário & undirected \\
\hline
\end{tabular}

Após esses procedimentos de preparação, processaram-se os dados com a utilização do Gephi. Com essa inserção, é formada uma primeira rede que liga cada trabalho às suas palavras-chave bem como com outros trabalhos que usam as mesmas palavras.

A presença dessas duas informações na rede dificulta a identificação das centralidades, o que torna necessária a transformação da rede do modo dual-mode (trabalho-palavra) para o modo one-mode (palavra-palavra) ${ }^{2}$. Na rede dual mode, tem-se dois tipos de nós de natureza distintas - os trabalhos e as palavras - estabelecendo ligações entre si, as arestas, para cada coocorrência. Ao converter a rede dual mode para one mode, suprimem-se os nós que representam os trabalhos, estabelecendo metaligações entre as palavras. A partir dessa nova rede gerada, são efetuados os cálculos da rede, como se pode visualizar na Figura 01.

Após a conversão da rede para o modo palavra-palavra, são executados os cálculos da rede no software, com destaque para o grau, grau ponderado e modularidade. O grau corresponde ao número de arestas ou relacionamentos apresentados por um nó. Já o grau ponderado é baseado no peso das arestas de um nó. A modularidade é fundamental para identificar as comunidades da rede (Newman, 2006). A modularidade é uma métrica de rede, não de nó, e se refere ao algoritmo utilizado para observar o número de partições de um determinado grafo. Trata-se, basicamente, de identificar nós fortemente conectados entre si e mais fracamente conectados com o restante da rede, podendo se caracterizar assim como uma comunidade temática (Newman, 2010, p. 372-382). O algoritmo de deteç̧ão de comunidades no Gephi pode ser ajustado às necessidades de pesquisa através da resolução de modularidade. Valores superiores a 1.0 implicam a geração de um número menor de comunidades maiores, enquanto valores inferiores a este valor implicam o seu contrário (Lambiotte et. al, 2014). Para o presente trabalho, utilizou-se a resolução 1.3 para geração de comunidades.

${ }^{2}$ Ver Newman (2010, p. 124-126). 

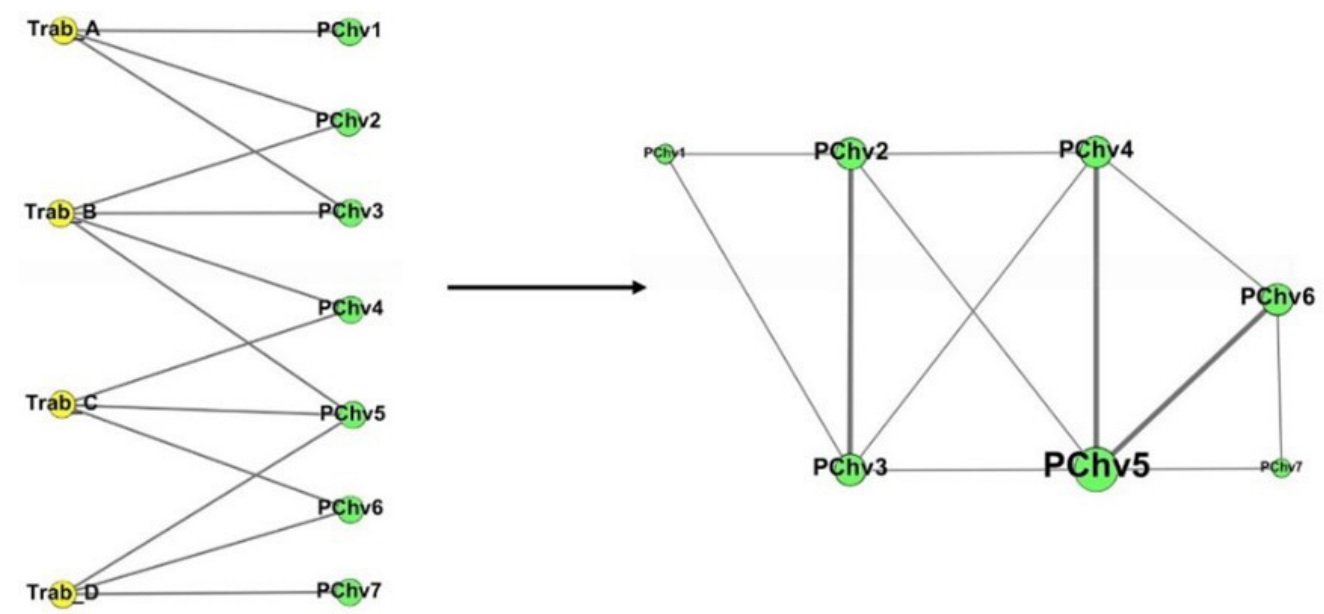

FIGURA 1 - Conversão rede dual mode (trabalho-palavra) para one mode (palavra-palavra).

\section{A pós-graduação em ciências ambientais no Brasil e sua produção}

Como apontado, um marco no desenvolvimento da formação de pesquisas interdisciplinares sobre as questões ambientais no Brasil foi a realização do $1^{\circ}$ Seminário Nacional sobre Universidade e Meio Ambiente, em 1986. A partir de então, inicia-se um movimento de incorporação do debate sobre o meio ambiente e os problemas ambientais no Brasil, auxiliado por incentivos específicos, como o PADCT Ciamb, na qual a interdisciplinaridade vai se constituindo como característica fundamental (Philippi Jr., 2000)

As ciências ambientais como área de avaliação específica da CAPES foi criada apenas em 2011, agrupando principalmente programas que anteriormente estavam na $4^{\mathrm{a}}$ câmara da área interdisciplinar, "Meio Ambiente e Agrárias", bem como programas da Área Interdisciplinar e de outras áreas com características e afinidades temáticas, como Ciências
Agrárias, Engenharia I, Engenharia III e Ciências Biológicas I (CAPES, 2013; CAPES, 2017). Em 2011, 57 programas migraram para nova área. O número chegou a $123 \mathrm{em} 2018$.

Cabe ressaltar que o crescimento da pós-graduação em ciências ambientais reflete o ocorrido na pós-graduação brasileira de forma geral, particularmente a partir de 2003. Houve um incremento significativo de programas em todas as áreas, bem como de programas stricto sensu em universidades particulares, haja vista que a criação desses programas se tornou obrigatória para que as instituições de ensino superior particulares ascendessem ao status de universidade (Cirani et al., 2015). Em 2018, nos 123 programas mencionados, 34 ofertavam mestrado e doutorado, 56 apenas mestrado, 5 apenas doutorado e 28 mestrados profissionais. Em termos regionais, a região com maior número de programas é o Sudeste (37), seguida pelo Sul (27) e Nordeste (27), o Centro-Oeste (18) e o Norte (14)

No que diz respeito à produção de teses e dissertações, entre 1994 (primeiro trabalho defen- 
dido) e 2017, foram defendidos nos programas que compõem a área de ciências ambientais um total de 12.642 teses e dissertações, sendo 8.902 dissertações em mestrados acadêmicos, 2.090 dissertações em mestrados profissionais e 1.640 teses. Desses, 1.061 apresentaram o desenvolvimento como temática - 715 dissertações em mestrados acadêmicos, $179 \mathrm{em}$ mestrados profissionalizantes e 167 teses de doutorado.

Em relação à distribuição regional, é interessante destacar a região Nordeste, que produziu $31,4 \%$ das teses e dissertações das CiAmb em geral, mas $41 \%$ de todas as teses e dissertações que abordaram a problemática do desenvolvimento. Isso mostra a importância da agenda de pesquisa sobre o desenvolvimento na região, reforçando o entendimento de como as especificidades regionais as influenciam, ao se considerar o histórico da região e os problemas socioeconômicos que enfrenta, com os maiores índices de pobreza do país (IBGE, 2017), lidos em algumas matrizes interpretativas como deficit de desenvolvimento. A segunda região que apresentou o maior número de trabalhos com a palavra desenvolvimento foi o Centro-Oeste, com $23 \%$, seguido do Sudeste, com $15 \%$, Sul, com $14 \%$ e, por fim, a região Norte, com apenas $6 \%$.

\section{As comunidades temáticas em torno da questão do desenvolvimento nas ciências ambientais}

\subsection{As palavras-chave}

Nos 1.061 trabalhos que compõem a base dessa pesquisa, foram identificadas - excluindo-se os termos desenvolvimento, sustentável, ambiental e correlatos - o uso de 1.238 palavras-chave diferentes. Elas são os nós da rede, estabelecendo 8.881 relacionamentos entre palavras, que representam os vértices ou arestas.

As palavras que apareceram com maior frequência e têm mais relações - e que por conseguinte terão maior grau ponderado e serão os nós mais centrais na rede - foram política, pública, local, turismo, rural, gestão, território, social, agricultura, educação, indicador, economia, urbano, regional, familiar, produção, comunidade, conservação, impacto, socioambiental, recurso, tecnologia, alimentar e sistema (Tabela 2).

O ranking da Tabela 2 expressa uma primeira aproximação do léxico utilizado nos trabalhos. Ele permite identificar os temas mais centrais dentro da agenda de pesquisa que envolve o desenvolvimento nas ciências ambientais. As palavras política e pública são as que têm maior grau e maior grau ponderado, relevando o forte peso dado ao papel dos governos no enfrentamento das questões relacionadas ao meio ambiente e ao desenvolvimento no país. Recortes espaciais, como rural, território, urbano, regional e local, que surgem como elementos importantes - são em geral qualificadores da noção de desenvolvimento. Todavia, mais importante que o quantitativo de relacionamentos é a condição qualitativa que pode ser extraída por meio da detecção de sub-redes, ou módulos da rede geral formados pela geodésica entre as palavras, que denominamos de comunidades temáticas.

\subsection{As comunidades temáticas}

Ao aplicar o algoritmo de modularidade com resolução 1.3, o resultado foi a identificação de dez 
comunidades temáticas. Duas comunidades são maiores: Política-Pública e Local-Turismo. Juntas elas abrangem quase $43 \%$ dos nós da rede. Cinco comunidades intermediárias: Economia-Tecnologia, Socioambiental-Impacto, Agricultura-Familiar, Indicador-Água e Saúde-Humano - que repre- sentam cerca de $43 \%$ da rede. Três comunidades pequenas: Resíduo-Sólido, Pesca-Indústria e Crédito-Limpo formam o restante da rede, com cerca de $14 \%$ (Tabela 3 ).

O grafo geral da rede, com suas 10 comunidades temáticas pode ser visualizado na Figura 2.

TABELA 2 - Palavras-chave ordenadas por grau ponderado.

\begin{tabular}{|c|c|c|c|c|c|c|}
\hline & Palavra & Grau & Grau ponderado & Palavra & Grau & Grau ponderado \\
\hline 1 & Política & 242 & 557 & Avaliação & 87 & 134 \\
\hline 2 & Pública & 215 & 508 & Água & 86 & 132 \\
\hline 3 & Local & 250 & 443 & Unidade & 78 & 131 \\
\hline 4 & Rural & 168 & 428 & Humano & 93 & 123 \\
\hline 5 & Território & 171 & 418 & Saúde & 92 & 123 \\
\hline 6 & Social & 196 & 391 & Recurso & 73 & 123 \\
\hline 7 & Turismo & 151 & 329 & Análise & 90 & 116 \\
\hline 8 & Agricultura & 146 & 322 & Qualidade & 79 & 114 \\
\hline 9 & Gestão & 169 & 307 & Área & 80 & 112 \\
\hline 10 & Economia & 169 & 292 & Planejamento & 73 & 112 \\
\hline 11 & Regional & 163 & 270 & Participação & 71 & 109 \\
\hline 12 & Urbano & 140 & 254 & Sólido & 64 & 109 \\
\hline 13 & Familiar & 122 & 242 & Vida & 70 & 107 \\
\hline 14 & Produção & 131 & 220 & Agroecologia & 58 & 106 \\
\hline 15 & Conservação & 111 & 213 & Trabalho & 67 & 102 \\
\hline 16 & Comunidade & 106 & 206 & Programa & 44 & 102 \\
\hline 17 & Sistema & 108 & 199 & Governança & 56 & 101 \\
\hline 18 & Educação & 133 & 188 & Amazônia & 74 & 99 \\
\hline 19 & Indicador & 122 & 185 & Cultura & 64 & 97 \\
\hline 20 & Alimentar & 86 & 164 & Energia & 59 & 94 \\
\hline 21 & Tecnologia & 81 & 163 & Uso & 64 & 93 \\
\hline 22 & Socioambiental & 93 & 148 & Semiárido & 62 & 93 \\
\hline 23 & Resíduo & 91 & 148 & Agrária & 52 & 93 \\
\hline 24 & Impacto & 96 & 147 & Hídrico & 52 & 93 \\
\hline 25 & Institucional & 99 & 146 & Nacional & 52 & 93 \\
\hline
\end{tabular}


TABELA 3 - Comunidades temáticas.

\begin{tabular}{lccc}
\hline Comunidade & Nós & Arestas & \% dos nós \\
\hline Política - Pública & 295 & 1492 & 23,83 \\
\hline Local - Turismo & 249 & 858 & 20,11 \\
\hline $\begin{array}{l}\text { Economia - Tecno- } \\
\text { logia }\end{array}$ & 131 & 483 & 10,58 \\
\hline $\begin{array}{l}\text { Socioambiental - } \\
\text { Impacto }\end{array}$ & 113 & 295 & 9,13 \\
\hline $\begin{array}{l}\text { Agricultura - fa- } \\
\text { miliar }\end{array}$ & 110 & 449 & 8,89 \\
\hline $\begin{array}{l}\text { Indicador - Água } \\
\text { Saúde - Humano }\end{array}$ & 96 & 252 & 7,75 \\
\hline Resíduo - Sólido & 70 & 373 & 6,79 \\
\hline Pesca - Indústria & 55 & 255 & 5,65 \\
\hline Crédito - limpo & 35 & 122 & 4,44 \\
\hline & $\mathbf{1 2 3 8}$ & $\mathbf{4 8 2 0}$ & $\mathbf{1 0 0}$ \\
\hline
\end{tabular}

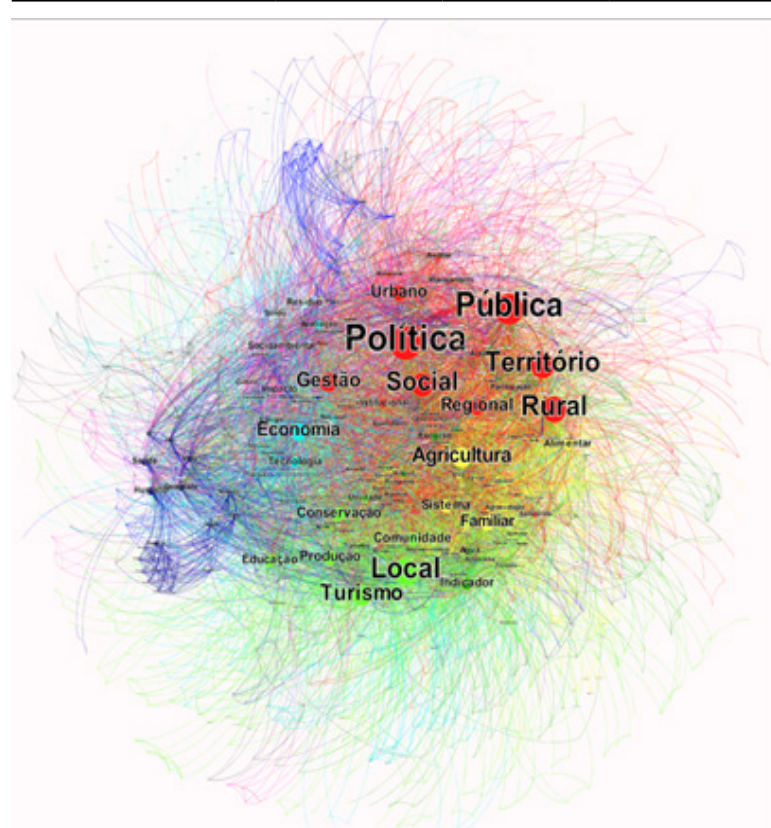

FIGURA 2 - Rede geral - desenvolvimento nas ciências ambientais e comunidades temáticas.
5.2.1. As grandes comunidades: políticas públicas e turismo - local

As duas maiores comunidades da rede são política-pública e local - turismo. Essas duas comunidades temáticas perfazem $43 \%$ dos nós da rede (Figura 3).

A maior comunidade identificada tem como palavras centrais política e pública. Essa comunidade é composta por 295 nós e 1.492 arestas. Além do termo-chave política - pública, outras palavras dessa comunidade que têm peso significativo na rede são: rural (grau ponderado 428), território (418), social (391), gestão (307), regional (270), urbano (254), institucional (146), análise (116), planejamento (112), participação (109) e governança (101).

É muito pertinente que esta comunidade seja a maior comunidade da rede, com $23,83 \%$. Isso aponta para a importância dada pelos pesquisadores às políticas públicas no processo de desenvolvimento sustentável no país, enfocando o papel do Estado e dos governos. Historicamente, um dos debates centrais que envolvem a temática do desenvolvimento, em geral, e a do desenvolvimento sustentável em particular, diz respeito ao papel do Estado e do mercado. O processo de institucionalização da agenda ambiental por parte dos Estados e a regulação do acesso aos recursos naturais tiveram caráter preponderante no debate ambientalista desde sua emergência, na década de 1970. Tal ênfase sofreu uma inflexão, especialmente a partir dos anos 2000, momento a partir do qual os mecanismos de mercado passam a ganhar projeção em face da ascensão de propostas liberalizantes (Pierri, 2005). Tal fato se faz notar particularmente na Conferência das Nações Unidades para o Meio Ambiente de 2012, a Rio +20 (Guimarães \& Fontoura, 2012; Misoczky \& Böhm, 2012). 


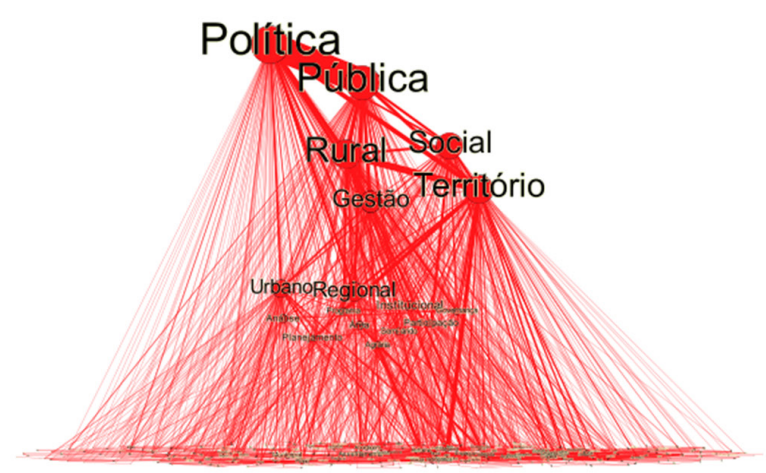

FIGURA 3 - Comunidades política - pública e turismo - local.

Em relação ao conteúdo dessas políticas públicas, há um destaque substantivo para aquelas ligadas ao rural, aos territórios, à região e ao urbano, destacando-se o caráter espacializado da pesquisa sobre essas políticas. Elas se dirigem a recortes espaciais específicos, abordagens bastante estabelecidas do debate sobre desenvolvimento. Destaca-se também o termo social, fator crucial no debate sobre desenvolvimento em países periféricos como o Brasil. Outros termos, como pobreza e cidadania, que remetem a um debate mais social, também compõem esse grupo.

Um aspecto interessante aqui é o peso maior do rural e do território em comparação aos recortes urbanos e regionais. Isto pode refletir a própria trajetória das ciências ambientais no país, visto que muitos programas hoje filiados à área de ciências ambientais antes estavam na Câmara de Meio Ambiente e Agrárias, revelando um interesse de pesquisadores em debater o rural brasileiro e seu desenvolvimento desde uma perspectiva interdisciplinar e com foco na questão ambiental. Uma leitura cronológica, que ultrapassa o recorte metodológico dessa pesquisa, poderia contribuir para identificar

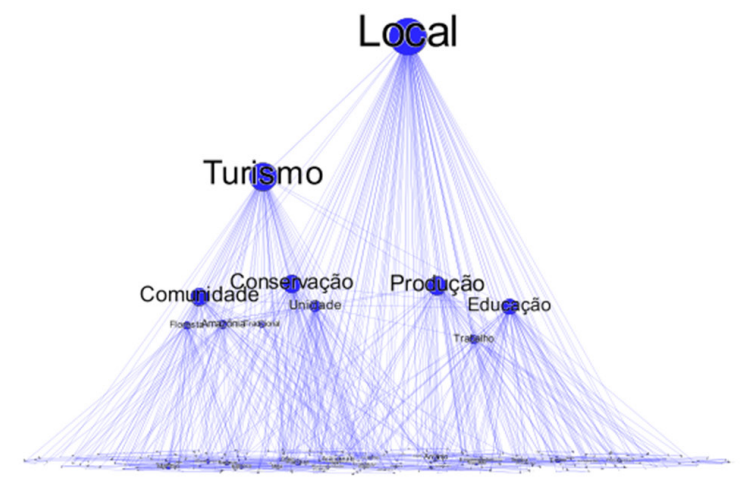

se houve mudanças na frequência desses recortes espaciais ao longo do tempo, mas é fato marcante a presença na agenda de pesquisa das ciências ambientais do debate sobre a ruralidade brasileira e seu desenvolvimento, um dos achados desta pesquisa.

Palavras que também aparecem com bastante peso nessa comunidade são gestão, planejamento, participação, governança, institucional, o que revela uma concentração no debate em torno de aspectos mais institucionais das políticas públicas.

Outro aspecto a observar, além do peso dos nós, é o peso das arestas entre nós. A aresta com maior peso, como se pode observar no grafo, conecta as palavras política e pública, com peso 93. Em seguida, as arestas com maior peso são rural - território (25), política - território (17), rural-política (16) e território - cidadania (14), o que confirma a centralidade do debate sobre as políticas públicas voltadas aos territórios rurais nesse grupo.

A segunda maior comunidade tem como palavras centrais Local - Turismo (Figura 1), é composta por 249 nós e 858 arestas. Além de local, termo com maior grau ponderado na comunidade (443), e turismo (329), aparecem nessa comunida- 
de termos como conservação (213), comunidade (206), produção (220), educação (188), unidade (131) e trabalho (102). Ao se observar o peso das arestas, as mais fortes são unidade - conservação (24), turismo - local (20), produção - local (17), turismo - comunidade (16), local - arranjo (12), tradicional - comunidade (10).

Esta é uma comunidade em que as temáticas envolvem desenvolvimento local, turismo, unidades de conservação, educação ambiental. Aparecem aqui também os trabalhos que tratam de arranjos produtivos locais, com destaque para comunidades tradicionais, unidades de conservação, turismo comunitário, educação ambiental. Nessa comunidade, há elementos ligados ao fato de o país ter uma das maiores biodiversidades do planeta, sendo alvo prioritário de políticas de conservação, entre elas, o estabelecimento de unidades de conservação.

O debate sobre o turismo e o desenvolvimento local envolve a formação de arranjos produtivos locais, o turismo comunitário e o empreendedorismo. É interessante destacar essa relação entre os termos turismo, desenvolvimento e conservação nesta comunidade, visto que a conservação da natureza é uma temática altamente relevante dentro das ciências ambientais. Porém, ao se buscar pela chave do desenvolvimento, a conservação aparecerá mais vinculada a alternativas produtivas que viabilizem e/ ou sejam compatíveis com a conservação, ganhando destaque a atividade turística, discussão presente na literatura brasileira, como em Irving et al. (2005).

\subsubsection{As comunidades intermediárias:}

economia-tecnologia, impactosocioambiental, agricultura-familiar, indicador-água e saúde-humano

São cinco as comunidades intermediárias, que juntas perfazem cerca de $43 \%$ dos nós (Figuras 4 , 5 e 6). A terceira comunidade temática da rede une economia e tecnologia como nós centrais, contando com 131 nós e 482 arestas. Os nós com maior grau ponderado nessa comunidade são: economia (292), tecnologia (169), avaliação (134), energia (94), nacional (93), ecológico (9), ciência (88), inovação (79), sociedade (68), solidária (63). As arestas principais são: economia - solidária (13), tecnologia - inovação (11), tecnologia - ciência (11), economia-ecológico (10). Aqui se reúnem trabalhos que abordam economia solidária, economia ecológica e questões relacionadas à ciência, tecnologia e inovação. O termo economia é o que une os dois distintos blocos temáticos dentro dessa comunidade. Como se pode observar no grafo, a comunidade se divide praticamente em duas partes, uma reunindo trabalhos com temas ligados à economia solidária e à economia ecológica, e outra fortemente voltada à ciência, à tecnologia e à inovação. A palavra-chave economia, que tem o maior grau na sub-rede, se liga a muitas outras palavras de baixo grau, mostrando uma variedade de temáticas e recortes de pesquisa sob o viés da economia nas ciências ambientais com foco no desenvolvimento, com ênfase na economia ecológica, abordagem de grande relevância nas ciências ambientais (Constanza et al., 2015), e na economia solidária - corrente importante do debate sobre alternativas populares de produção e consumo (Singer, 2002). 


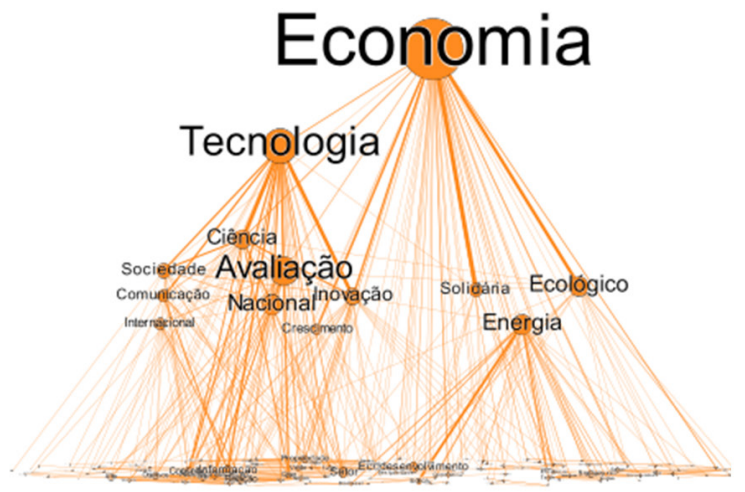

\section{Impacto} Socioambiental

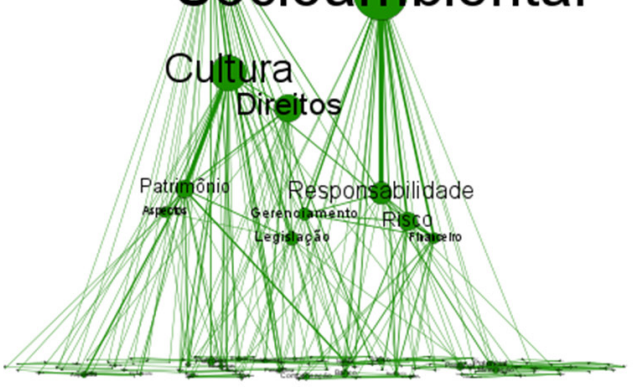

FIGURA 4 - Comunidades economia-tecnologia e impacto socioambiental.

A quarta comunidade temática da rede de desenvolvimento nas ciências ambientais é a impacto-socioambiental (Figura 4), com 113 dos nós e 295 arestas. Tem como nós principais: impacto (147), socioambiental (148), cultura (97), direitos (75), responsabilidade (60), risco (50), patrimônio (48). Nesta comunidade encontram-se trabalhos que versam sobre impactos ligados ao patrimônio cultural e à violação de direitos, oferecendo uma pertinente demonstração da dimensão socioambiental. Aparecem também trabalhos relacionados à responsabilidade socioambiental e aos riscos socioambientais.

A quinta comunidade, ainda no rol das intermediárias, é a consistente comunidade ligada à agricultura familiar, com 110 nós (Figura 5). O nó agricultura tem um grau ponderado significativo na rede - 322 (oitava no ranking, como se observa na Tabela 2), enquanto familiar aparece com 242, sistema com 199, alimentar com 106 e agroecologia com 106. Diferentemente da comunidade políticas públicas, na qual ficou o termo rural, na comunidade agricultura familiar os termos ligados à agricultura aparecem numa perspectiva de uma ruralidade produtiva e conectada aos sistemas alimentares. Nesse sentido, aparecem os termos sistema, alimentar, agroecologia, alimento, agroflorestal, uso do solo, agrícola, socioeconômico, com muitas ligações entre si.

Em seguida, figura a comunidade que reúne os trabalhos que versam sobre a temática da água, articulada pela palavra indicador, com 96 nós (Figura 5). Os nós com maior grau ponderado são: indicador (185), água (132), recurso (123), hídrico (93), índice (69). O conjunto de termos, em sua grande maioria, se refere à mesma chave temática, a água. Tem-se assim recursos hídricos, água, outorga, com uma abordagem comum nos trabalhos sobre recursos hídricos que são a construção de indicadores e índices.

A comunidade seguinte, ainda no rol das intermediárias, é a saúde - humano, que tem 84 nós e 373 arestas (Figura 6). Saúde (123), humano (123), qualidade (114), vida (107) são os nós com maior grau ponderado. Aparecem também clima (76), global (75), mudanças (74) e doenças (76). 
Trata-se, assim, de uma comunidade que tematiza questões relacionadas à qualidade de vida e às doenças, fazendo um forte elo com o tema das mudanças climáticas, aquecimento global e vulnerabilidade. Temos ainda as palavras índio, sul, terra, pecuária, relacionando, possivelmente, a agropecuária com a pressão sobre terras indígenas, ao mesmo tempo em que a agropecuária é um vetor de mudanças climáticas.

\section{Agricultura}

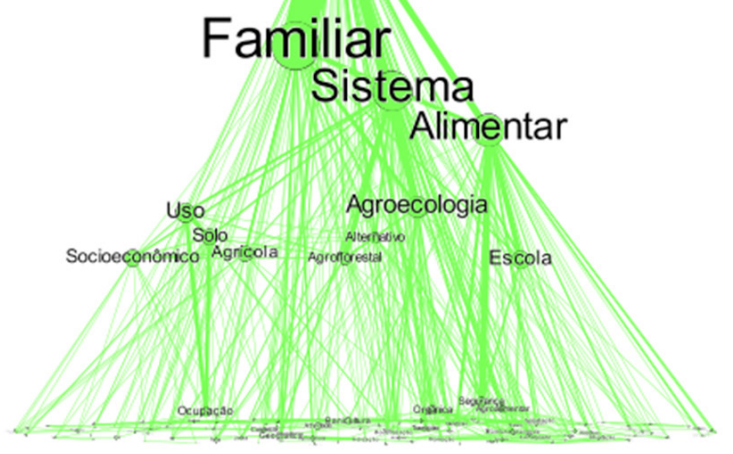

FIGURA 5 - Comunidades agricultura - familiar e indicador - água.

\section{Indicador}

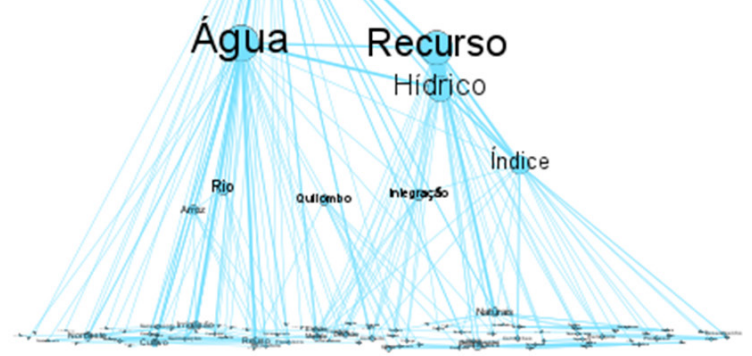

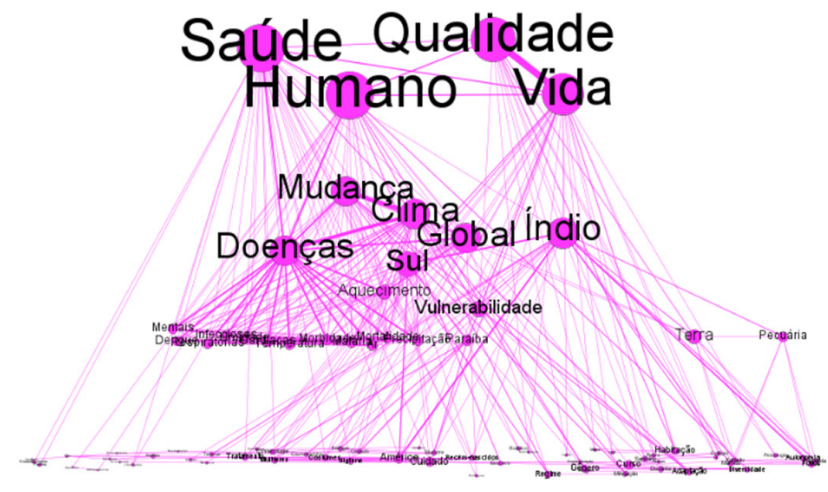

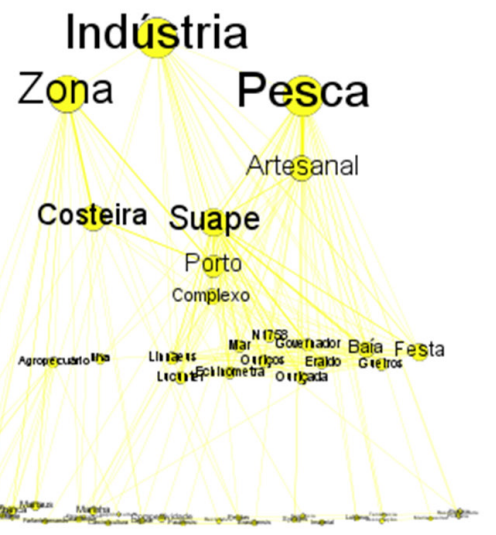

FIGURA 6 - Comunidades saúde-humano e indústria-pesca. 


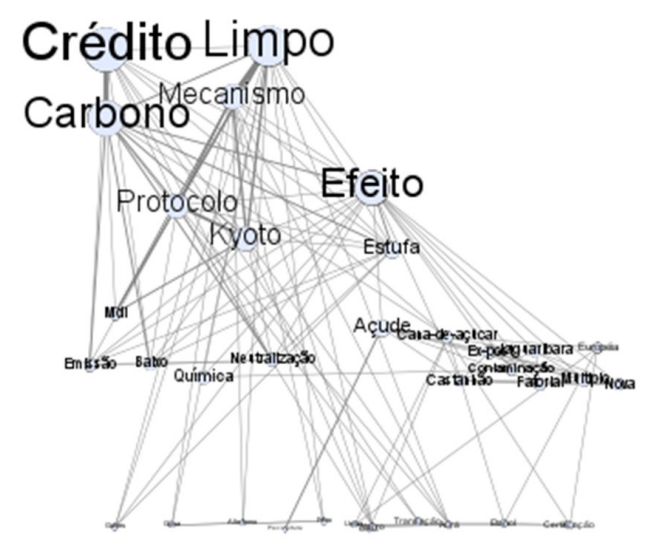

FIGURA 7 - Comunidades crédito - limpo e resíduo - sólido.

\subsubsection{As comunidades pequenas: pesca-} indústria, crédito - limpo, resíduo - sólido

As três comunidades pequenas (Figuras 6 e 7) são pesca-indústria, crédito-limpo e resíduo sólido, que somadas representam apenas $12,92 \%$ dos nós da rede. Na comunidade pesca-indústria (Figura 6) destacam-se também as palavras costeira, artesanal, Suape, mostrando um conjunto pequeno de trabalhos que tratam de impactos na zona costeira e sua relação com a pesca artesanal. Na comunidade crédito-limpo (Figura 7) destacam-se mecanismo, carbono, efeito estufa, mostrando igualmente um conjunto circunscrito de trabalhos que abordam especificamente essa temática, que fez com que ela se separasse da comunidade que une os trabalhos relacionados às mudanças climáticas, por exemplo, mais focados em vulnerabilidade e saúde. Por fim, tem-se a comunidade resíduo - sólido (Figura 7), na qual figuram tanto trabalhos que tratam de resíduos da construção civil quanto da reciclagem desses resíduos, trazendo também palavras que qualificam

\section{Resíduo Sólido}

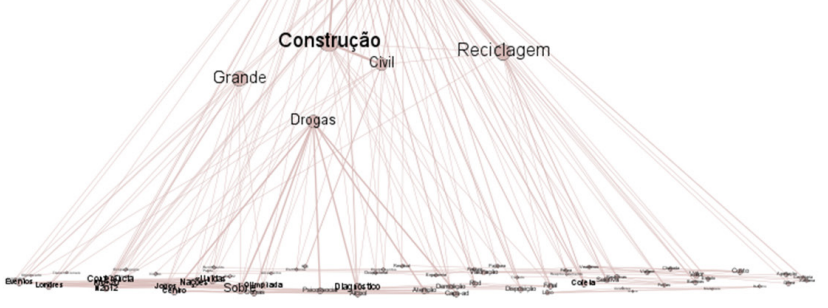

os tipos de resíduos, como esgoto, eletrônico, ou formas de destinação, como coleta, tratamento.

\section{Considerações finais}

A agenda de pesquisa das ciências ambientais, como uma área interdisciplinar, parece ter a prevalência, em termos globais, de abordagens do eixo ciência, tecnologia, engenharia e matemática, como indicam Castree et al. (2014). No Brasil, ainda não existem pesquisas sistemáticas que revelem na produção das ciências ambientais (i) o peso e composição de cada uma das áreas do conhecimento, (ii) as principais perspectivas teórico-metodológicas adotadas, (iii) nem quais as principais temáticas tratadas. No âmbito da América Latina, Valnhust \& Zaccai (2016) apontam para a adoção de perspectivas críticas por parte dos autores quando se trata da questão do desenvolvimento sustentável.

Ao realizar uma análise de agrupamentos com as linhas de pesquisa dos programas da área, no ano 
de 2013, Phillipi Jr. et al. identificaram desenvolvimento + meio ambiente, com frequência de $58 \%$; recursos naturais + ecologia, com 36\%; gestão + planejamento + políticas públicas, com $40 \%$; e tecnologia + modelagem, com $57 \%$, apontando (i) a diversidade de abordagens existentes dentro do campo, ao mesmo tempo e (ii) um balanceamento de temas entre as linhas de pesquisa dos programas da área no Brasil.

Portanto, a questão do desenvolvimento é presente e importante nas ciências ambientais brasileiras, mas até o momento há poucas investigações sobre como é composta essa agenda de pesquisa, contribuição que se buscou dar por meio desta pesquisa, com a análise dos temas trabalhados pelos autores a partir das palavras-chave.

A metodologia relacional proporcionada pela análise de redes é uma ferramenta potente para o trabalho com grandes fundos documentais, em lugar das bibliometrias tradicionais por atributos. É possível identificar comunidades temáticas, contribuindo para a reflexividade do campo e a identificação de elementos da agenda de pesquisa em torno da questão do desenvolvimento no âmbito das ciências ambientais.

A análise da agenda de pesquisa sobre desenvolvimento nas ciências ambientais a partir das teses e dissertações, com o uso da bibliometria relacional, revelou alguns de seus elementos centrais. Em primeiro lugar, a distribuição regional se destaca, fortemente concentrada no Nordeste do país, com 41\% dos 1.061 trabalhos identificados.

Em relação às temáticas, há uma grande diversidade, com a formação de 10 comunidades com focos bastante diversos entre si. O foco nas políticas públicas se destacou, com nós com maior grau ponderado de toda a rede e formadores da maior comunidade temática. Em relação à abordagem dessas políticas, ficaram evidentes os seus recortes espacializados - território, rural, urbano, regional - ao mesmo tempo em que ganharam relevância aspectos institucionais na análise dessas políticas, pelo peso das palavras institucional, planejamento, governança, gestão, entre outras.

As temáticas ligadas ao rural também apareceram com destaque. Além do alto grau do nó rural, que apareceu como um qualificador na comunidade de políticas públicas, formou-se outra comunidade com centralidade para agricultura familiar, num viés da ruralidade produtiva e com destaque para os sistemas alimentares. Isso revela a importância da abordagem do rural dentro das ciências ambientais brasileiras voltadas para a questão do desenvolvimento, o que está ligado à própria trajetória institucional do campo no país, visto que muitos programas que pertencem atualmente a CiAmb migraram da câmara Meio Ambiente e Agrárias.

Outro elemento que se sobressaiu entre os resultados foi a temática do turismo, cujo nó teve grau ponderado maior que temas altamente incidentes nas ciências ambientais, como economia e conservação. Pode-se inferir que essa centralidade se dá em razão de a atividade figurar como alternativa econômica importante para o desenvolvimento local - termo ao qual aparece relacionado na comunidade - em face, inclusive, da concentração regional dos trabalhos na região Nordeste, na qual a atividade turística tem peso importante.

É interessante notar que um tema altamente relevante na atualidade e que tem centralidade nas ciências ambientais globais, o das mudanças climáticas, não é um tema privilegiado desde a perspectiva do desenvolvimento, embora apareça entre as comunidades temáticas em duas articulações 
distintas. Na comunidade saúde-humano, em que o foco está principalmente nos agravos à saúde causados pelas mudanças climáticas, ligada a processos de vulnerabilização, e na comunidade crédito-carbono, uma comunidade pequena que reúne trabalhos que abordam mecanismos de desenvolvimento limpo ligados ao Protocolo de Kyoto.

Um tema importante para o país e que aparece com algum destaque é o da água. A palavra está entre as que alcançam maior grau na rede e se soma a recursos hídricos e indicador para compor uma comunidade temática coesa, apontando para sua importante interface com a temática do desenvolvimento.

Por fim, destaca-se o uso da bibliometria relacional e da análise de redes como metodologia que abre perspectivas para o mapeamento dos campos científicos, explorando repositórios documentais disponibilizados publicamente, como a base de dados da Capes. Inclui-se possibilidades de compreender relações entre universidades, regiões, pesquisadores, programas de pós-graduação em interface com os temas abordados, entre outras abordagens que têm uso crescente nos últimos anos e são fundamentais para reflexividade da própria ciência.

\section{Agradecimentos}

Agradecemos à CAPES pela bolsa de pós-doutorado que viabilizou a realização desta pesquisa.

\section{Referências}

Bettencourt, L.M.A.; Kaur, J. Evolution and structure of sustainability science. PNAS-Proceedings of the National Academy of Sciences, 108(49), 19540-19545, 2011. doi: 10.1073/pnas.1102712108

Björnberg, K. E.; Karlsson, M.; Gilek, M.; Hansson, S. O. Climate and environmental science denial: A review of the scientific literature published in 1990-2015. Journal of Cleaner Production, 167, 229-241, 2017. doi: 10.1016/j. jclepro.2017.08.066

Bourdieu, P. Os usos sociais da ciência: por uma sociologia clínica do campo científico. São Paulo: Editora da Unesp, 2004.

Buarque, C.; Ferreira, L. C.; Jacobi, P. R.; Sobral, M.C.; Sampaio, C. A. C.; Fernandes, V. A interdisciplinaridade e o enfrentamento aos desafios da sustentabilidade. Sustentabilidade Em Debate, 5(1), 183 - 195, 2014. doi: 10.18472/ SustDeb.v5n1.2014.10688

Bursztyn, M. Meio ambiente e interdisciplinaridade: desafios ao mundo acadêmico. Desenvolvimento e Meio Ambiente, 10, 67-76, 2004. doi: 10.5380/dma.v10i0.3095

Buter, R. K.; Van Raan, A. F. J. Identification and analysis of the highly cited knowledge base of sustainability science. Sustainability Science, 8, 253-267, 2013. doi: 10.1007/ s11625-012-0185-1

Buttel, F. H.; Hawkins, A. P.; Power, A. G. From limits to growth to global change. Global Environmental Change, 1(1), 57-66, 1990. doi: 10.1016/0959-3780(90)90007-V

CAPES - Coordenação De Aperfeiçoamento De Pessoal De Nível Superior. Documento de área - ciências ambientais. Brasília, 2013. Disponível em: https://www.gov.br/capes/ pt-br/centrais-de-conteudo/Ciencias_Ambientais_doc_area_e_comisso01.pdf

CAPES - Coordenação De Aperfeiçoamento De Pessoal De Nível Superior. Relatório de avalição - ciências ambientais. Avaliação quadrienal 2017. Brasília, 2017. Disponível em: https://www.gov.br/capes/pt-br/centrais-de-conteudo/ 20122017CIENCIASAMBIENTAISquadrienal.pdf

Carson, R. Silent spring. Boston: Houghton Mifflin, 1962.

Castree, N. et al. Changing the intellectual climate. Nature Climate Change, 4, 763-768, 2014. doi: 10.1038/NCLIMATE2339

Castree, N. Broaden research on the human dimensions of 
climate change. Nature Climate Change, 6, 731, 2016. Doi: 10.1038/nclimate3078

Cavalcanti, D. B. F.; Leite, B. R. A. Interdisciplinaridade e estudos métricos da informação. Informação em Pauta, 4(1), 68-81, 2019. doi: 10.32810/2525-3468.ip. v4i1.2019.41319.68-81

Cirani, C. B. S.; Campanario, M. A.; Silva, H. H. M. A evolução do ensino da pós-graduação senso estrito no Brasil: análise exploratória e proposições para pesquisa. Avaliação, 20(1),163-187, 2015. doi: 10.590/S141440772015000500011

Commoner, B. Science and survival. New York: Viking Press, 1966.

Constanza, R.; Cumberland, J. H.; Daly, H.; Goodland, R.; Norgaard, R.; Kubiszewski, I.; Franco, C. An introduction to ecological economics. New Yortk: CRC Press, 2a ed., 2015.

Crutzen, P. J. Geology of Mankind: The Anthropocene. Nature, 415, 23, 2002. doi: 10.1038/415023a

Cunningham, W. P.; Cunningham, M. A. Environmental science: a global concern. New York: McGraw-Hill, $10^{\text {th }}$ ed., 2008.

Erlich, P. R. The population bomb. New York: Ballantine Books, 1966.

Estenssoro, F. El ecodesarrollo como concepto precursor del desarrollo sustentable y su influencia en America Latina. Universum, 30(1), 81-99, 2015. Disponível em $<$ https://scielo.conicyt.cl/scielo.php?script=sci arttext\&pi$\mathrm{d}=\mathrm{S} 0718-23762015000100006 \& \operatorname{lng}=\mathrm{es} \& \mathrm{nrm}=$ iso $>$

Ferreira, L. C. Ambiente e sociedade na teoria social: construindo a interdisciplinaridade. Teoria e pesquisa, 48, 93-104, 2006. Disponível em: http://www.teoriaepesquisa. ufscar.br/index.php/tp/article/view/15/6

Feretti, V.; Junckes, I. J.; Clemente, A. J. Ciência política e análise de redes: uma metodologia para o mapeamento de comunidades temáticas. Guaju - Revista Brasileira de Desenvolvimento Territorial Sustentável, 4(2), 2018, 229251. doi: $10.5380 /$ guaju.v4i2.57497

Floriani, D. Diálogos interdisciplinares para uma agenda socioambiental: breve inventário do debate sobre ciência, sociedade e natureza. Desenvolvimento e Meio Ambiente, 1, 21-40, 2000. doi: 10.5380/dma.v1i0.3055

Foladori, F. Uma tipologia del pensamento ambientalista. Foladori, G.; Pierri, N. Sustentabilidad? Desacuerdos sobre el desarollo sustentable. Mexico: Universidad de Zacatecas, 2005, p.83-136.

Forsyth, T. Critical political ecology: the politics of environmental science. Londres: Routledge, 2003.

Guevara, F. G. L. Aportes para una Caracterización de las Ciencias Ambientales. In: Saénz, O. Las ciencias ambientales: una nueva área del conocimiento. Bogotá (Colombia): Red Colombiana de Formación Ambiental, RCFA.

Guimarães, R. P.; Fontoura, Y. S. R. Rio+20 ou Rio20?: crônica de um fracasso anunciado. Ambiente \& Sociedade, 15(3), 19-39, 2012. doi: 10.1590/S1414753X2012000300003

Hassan, S. U.; Haddawy, P.; Zhu, J. A bibliometric study of the world's research activity in sustainable development and its sub-areas using scientific literature. Scientometrics, 99(2), 549-579, 2013. doi: 10.1007/s11192-013-1193-3

Irving, M. A.; Bursztyn, I.; Sancho, A. P.; Melo, G. M. Revisitando significados em sustentabilidade no planejamento turístico. Caderno Virtual de Turismo, 5(4), 1-7, 2005. Disponível em: https://www.redalyc.org/ pdf/1154/115416146001.pdf

Lélé, S. M. Sustainable development: A critical review. World Development, 19(6), 607-621, 1991. doi: 10.1016/0305-750x(91)90197

Leff, E. Racionalidade ambiental: a reapropriação social da natureza. Rio de Janeiro: Civilização Brasileira, 2006.

Hayashi, M. C. P. I. Sociologia da ciência, bibliometria e cientometria: contribuições para a análise da produção científica. In: Anais eletrônico - IV EPISTED - Seminário de epistemologia e teorias da educação. Campinas, 2012.

Hopwood, B.; Mellor, M.; O’Brien, G. Sustainable development: mapping different approaches. Sustainable Development, 13(1), p.38-52, 2005. doi: 10.1002/sd.244

IBGE - Instituto Brasileiro de Geografia e Estatística. Síntese de indicadores sociais: uma análise das condições de 
vida da população brasileira. Rio de Janeiro: IBGE, 2017.

Lambiotte, R.; Delvenne, J.; Barahona, M. Random Walks, Markov Processes and the Multiscale Modular Organization of Complex Networks. IEEE Transactions on Network Science and Engineering, 1(2), 76-90, 2014. doi: 10.1109/ TNSE.2015.2391998

Meadows, D.; Meadows, D.; Randers, J.; Behrens, W.W. (Orgs.). The limits to growth. New York: Universe books, 1972.

Misoczky, M. C., Böhm, S. Do desenvolvimento sustentável à economia verde: a constante e acelerada investida do capital sobre a natureza. Cadernos EBAPE.BR, 10(3), 546-568, 2012. doi: 10.1590/S1679-39512012000300006

Moore, J. W. The Capitalocene, Part I: on the nature and origins of our ecological crisis. The Journal of Peasant Studies, 44(3), 594-630, 2017. doi: 10.1080/03066150.2016.1235036

Montibeller Filho, G. O mito do desenvolvimento sustentável: meio ambiente e custos sociais no moderno sistema produtor de mercadorias. Florianópolis: Editora da UFSC, $3^{\mathrm{a}}$ ed., 2008.

Newman, M. E. J. Modularity and community structure in networks. Proceedings of the National Academy of Sciences, 103(23), 8577-8582; 2006. doi: 10.1073/pnas.0601602103

Newman, M. Networks: an introduction. Oxford: Oxford University Press, 2010.

Paranyushkin, D. Identifying the Pathways for Meaning Circulation using Text Network Analysis. Venture Fiction Practices, 2(4), 2011. Disponível em: https://noduslabs. com/wp-content/uploads/2012/04/Pathways-Meaning-Text-Network-Analysis.pdf

Philippi Jr., A. A interdisciplinaridade como atributo da C\&T. In: Philippi Jr., A.; Tucci, C. E. M; Hogan, D. J.; Navegantes, R. (Orgs.). Interdisciplinaridade em Ciências Ambientais. São Paulo: Signus Editora, 2000.

Philippi Jr., A; Tucci, C. E. M; Hogan, D. J.; Navegantes, R. Uma Visão Atual e Futura da Interdisciplinaridade em C\&T Ambiental. In: Philippi Jr., A.; Tucci, C. E. M; Hogan, D. J.; Navegantes, R. (Orgs.). Interdisciplinaridade em Ciências Ambientais. São Paulo: Signus Editora, 2000.
Philippi Jr., A.; Sampaio, C. A. C.; Sobral, M. C.; Fernandes, V. Desenvolvimento sustentável, interdisciplinaridade e Ciências Ambientais. RBPG, 10(21), 509 - 533, 2013. doi: 10.21713/2358-2332.2013.v10.423

Pierri, N. Historico del concepto de desarrollo sustentable. In: Foladori, G.; Pierri, N. Sustentabilidad? Desacuerdos sobre el desarollo sustentable. Mexico: Universidad de Zacatecas, 2005, p. 83-136.

Radhakrishnan, S.; Erbis, S.; Isaacs, J. A.; Kamarthi, S. Novel keyword co-occurrence network-based methods to foster systematic reviews of scientific literature. Plos One, 12(9), 2017 e0185771. doi: 10.1371/journal.\%20pone.0172778

Raimbault, J. Exploration of an interdisciplinary scientific landscape. Scientometrics 119, 617-641, 2019. doi: 10.1007/s11192-019-03090-3

Rocha, P. E. D. Trajetórias e perspectivas da interdisciplinaridade ambiental na pós-graduação brasileira. Ambiente \& Sociedade, 6(2), 155-182, 2003. Disponível em: https:// www.scielo.br/pdf/asoc/v6n2/a10v06n2.pdf

Santos, B. S. Um discurso sobre as ciências. São Paulo: Cortez, $5^{\mathrm{a}}$ ed., 2008.

Schodl, K.; Klein, F.; Winckler, C. Mapping sustainability in pig farming research using keyword network analysis. Livestock Science, 196, 28-35, 2017. doi: 10.1016/j.livsci.2016.12.005

Silva, E. A.; Pereira, M. A. M. Balanço aos 20: a Revista de História Regional no campo historiográfico brasileiro. Revista de História Regional, 21(2), 307-337, 2016. Disponível em: https://www.revistas2.uepg.br/index.php/rhr/ article/view/9490

Silva, E. A.; Silva, J. M. Ofício, engenho e arte: inspiração e técnica na análise de dados qualitativos. Revista latino-americana de Geografia e Gênero,7(1), 132-154, 2016. doi: 10.5212/Rlagg.v.7.i1.0009

Silva, R. G. L.; Costa, M. C. Sociologia da Ciência e da Tecnologia: instrumentos para a análise do processo de formação de agendas de pesquisa. In: Campos, C.; Marinho, G. S. M. C.; Monteiro, M.; Dias, R. B.; Silveira, S. A. Abordagens em ciência, tecnologia e sociedade. Santo André: Editora da UFABC, 2015. 
Singer, P. A recente ressurreição da economia solidária no Brasil. In: Santos, B. S. (Org.). Produzir para viver: os caminhos da produção não capitalista. Rio de janeiro: Civilização Brasileira, 2002.

Thelwall, M. Bibliometrics to webometrics. Journal of Information Science, 34 (4) 605-621, 2008. doi: $10.1177 / 0165551507087238$

Vanhulst, J.; Zaccai, E. Sustainability in latin America: An analysis of the academic discursive field. Environmental Development, 20, 68-82, 2016. doi: 10.1016/j. envdev.2016.10.005
Vieira, P. F. Políticas ambientais no Brasil: Do preservacionismo ao desenvolvimento territorial sustentável. Política e sociedade, 14, 27-75, 2009.

Yi, S.; Choi, J. The organization of scientific knowledge: the structural characteristics of keyword networks. Scientometrics, 90(3), 1015-1026, 2012. doi:10.1007/s11192011-0560-1 